\title{
Reversing the Trend of Educational Disparity in West Africa
}

\author{
Stephen Bolaji (Corresponding author) \\ International Graduate Centre of Education, College of Education \\ Charles Darwin University, Australia \\ E-mail: stephen.bolaji@cdu.edu.au \\ Sullay Jalloh, Bisi Imonitie \& Abdulai Walon-Jalloh \\ International Graduate Centre of Education, College of Education \\ Charles Darwin University, Australia
}

Received: May 3, 2018 Accepted: June 12, 2018 Published: June 25, 2018

doi:10.5296/ijld.v8i2.13089 URL: https://doi.org/10.5296/ijld.v8i2.13089

\begin{abstract}
This study was an outcome of research report on closing the gap of educational disparities in two West Africa countries (Nigeria and Sierra Leone). Both countries were among the 155 countries that agreed at the World Conference on 'Education for All' in Jomtien (1990), to make primary education accessible to all children and to massively reduce illiteracy before the end of the decade. There has been little demonstrated success since the implementation of the UBE program over a decade ago. Findings from the analysed data collected through document analysis and interview with thirty bureaucrats in the capital Territories of the two countries revealed that more than eight million children of school age (six to 15 years) are still not in school in Nigeria (Bolaji, Campbell-Evans and Gray, 2016; NUT, 2008; UENSCO, 2006; World Bank, 2007, UBEC, 2004), and over $28 \%$ of school-aged children are out of school and those children that have dropped out of school are engaged in domestic and economic slavery in Sierra Leone(World Bank Report, 2014; UNICEF Report, 2009; 2015). Meeting the United Nations (UN) Millennium Development Goals (MDGs), which aim to achieve compulsory universal basic education for all children 2050, is in serious doubt in both countries because of the issue of implementation. This study advocates regional managerialism of education as alternative approach to achieving education for all in 2050.
\end{abstract}

Keywords: Education, autonomy, education policy, Nigeria and Sierra Leone 


\section{Introduction}

This study investigated 'Education for All' (EFA) policy implementation in Nigeria and Sierra Leone. The two countries have common historical heritage as former British colonies and through their developmental process of education system since colonial dispensation. Nigeria is located in Western Africa on the Gulf of Guinea and has a total area of 923,768 $\mathrm{km} 2$, making it the world's thirty-second largest country. It is comparable in size to Venezuela, is about twice the size of California, and is one-third of the size of Western Australia. Nigeria has a varied landscape with the most expansive topographical region. The country is comprised of three large ethnic groups: the Yoruba, Hausa-Fulani and Igbo. The country's official language is English, which is widely spoken by the people and as a medium of instruction at all level of schooling. Sierra Leone has a total landscape area of 27,699sq and a population of 6.1 million people. Sierra Leone has a special historical significance as the transatlantic slave trade departure point for thousands of West African captives. The capital, Freetown, was founded as a home for repatriated former slaves in 1787. English Language is the official and widely spoken, especially among the educated people. Krio (Creole language derived from English) and a range of African languages are widely spoken among the illiterate people of Sierra Leone.

Education has been regarded the only enduring legacy among the former British West Africa colonies. This shared understanding made the government of Nigeria and Sierra Leone to initiate policy directions for their respective countries. The governments' initiatives centred on removing distortions and inconsistencies in the basic education delivery and reinforce the colonial legacy to provide greater access to, and ensure quality of, basic education throughout. The World Conference on 'Education for All' in Jomtien (1990), re-energized the commitment of both countries towards ensuring un-interrupted access to 9-year formal education by providing free, compulsory UBE for every child of school going age; reduce school drop-out and improve relevance, quality and efficiency; and acquire literacy, numeracy, life skills and values for lifelong education and useful living. This shared commitment among the two countries led to the introduction of Universal Basic Education in 1999 in Nigeria, and Sierra Leone in 2001.

Prior to introduction of the UBE in Nigeria 1999, issues of access, equity, retention and quality enhancement were the challenges that militated against quality of education delivery (Bolaji, Campbell-Evans and Gray, 2015; 2016). Pupil absenteeisms and high drop-outs were serious problems especially in primary schools and there was ample evidence of poor performance of pupils as they came up through system. For instance, Table 1 shows the enrolment trends between 1990 and 1998 which indicates that there were increases in access to schooling by both sexes, but by 1995, there was a great decline as well as inequality in the enrolment of boys and girls. 
Table 1. The enrolment trends of boys and girls between1995-1998

\begin{tabular}{llll}
\hline Year & Boys\% & Girls\% & Total\% \\
\hline 1990 & 76.4 & 59.1 & 67.7 \\
1991 & 86.6 & 69.1 & 77.1 \\
1992 & 90.3 & 71.9 & 81.1 \\
1993 & 93.6 & 74.7 & 84.1 \\
1994 & 89.4 & 83.2 & 86.5 \\
1995 & 85.5 & 74.9 & 80.6 \\
$1996-1998$ & 76.0 & 66.0 & 71.0
\end{tabular}

Sources: Adapted from the statistics of Primary and Post-Primary Education in Nigeria, Federal Ministry of Education, Lagos, 1994/1995 and Lawal (2007).

The drop-out syndrome (the drop-out rate of Nigerian children from school) prompted national, state and community advocacy. While attempts were made in getting more girls to complete primary school, economic pressures appear to influence early withdrawal of boys, especially in the southern part of Nigeria. The emerging indices were that where once boys tended to drop out at secondary school level, they now (1997) do so at the primary level. This was an indicator of the country's economic decline as well as perception of the utility value of the education system (UNICEF Report, 1997).

Similarly, up untill 2001, Sierra Leone could be regarded as abysmal state because of the civil war (1995-2001) that ravaged the entire country for over a decade and contributed to the decline in the educational opportunities available for the citizen. For instance, during the period of war, over $67 \%$ of all school-age children were out of school and none of the 1270 classrooms in the country were habitable for any meaningful learning engagement (US Bureau, 2002). The situation in both countries attracted the much needed assistance from international agencies such as World Bank, USAID, UNICEF, UNESCO and many others, in the form of grants and loans to ensure the implementation of the new policy commitment for free and compulsory basic education. Apart from the international obligations, the governments of both countries through the legislative assembly enacted the basic education law in 2004 and 2006 respectively, as a national obligation for the achievement of basic education through the promulgation of policies. Assessment reports by the World Bank and other international donors in 2007 envisaged a full course of schooling for all by 2015 that will eliminate all gender disparity and resolved the challenge of disarticulation- transition process from primary to secondary schools.

It has been over a decade since the UBE policy was introduced, the implementation of the policy in both countries still at negligible performance index (Bolaji, et al, 2015; 2016; UNESCO Report, 2015). More than eight million Nigerian children under the age of 14 lack access to basic education programme (NUT, 2004; UNESCO, 2006 and UNICEF, 2010; UNESCO, 2015). UNICEF (2010) reported that Nigeria keeps the unenviable world record of 
harbouring the largest number of out-of-school children, after Pakistan. In Sierra Leone, 28\% of school aged children are out of school and those children that have dropped out of school are engaged in domestic and economic slavery (World Bank Report, 2014; UNICEF Report, 2010; UNESCO, 2015). There is wide gap of disparity, majority of children in the remote and rural areas of the country still do not have access to basic education, and the transition to secondary schools have not been well articulated because of the challenge of disarticulation (UNESCO Report, 2015). While the goals of achieving access to education in these countries are worthy, the implementation has been wanting. There is a saying that when educational opportunities are not provided early for youths, educating them when they are adults becomes problematic. Thus, access to educational opportunity is pivotal to nation's development. It was against this background that this study was initiated.

\subsection{The Problem}

The recent international assessments performance of basic education policy implementation in Nigeria and Sierra Leone has been considered negligible due to lack of adequate implementation (World Bank, 2014; UNESCO, 2015: Bolaji, et al 2016). The overall appraisal of the international donors towards education deliverables in these countries points to the challenge of bureaucratic mechanism of implementation process. Previous research has clearly shown that the actions of the bureaucrats in the developing countries are the major issues affecting the UBE implementation, particularly in Nigeria as it relates to access in UBE (Olarenwaju \& Folorunsho, 2009; Ogunjimi, Ajibola \& Akah, 2009; Obayan, 2011). Based on the above statement, it seems to us that the implementation strategies have been responsible for ineffective implementation of the UBE program in both nations. This study provides an opportunity to explore the challenges confronting the bureaucratic structure of UBE in post 2015 implementation.

\subsection{Research Question}

The two research questions examined in this study were:

1. Did the bureaucrats have the required skills, expertise and knowledge to drive the UBE policy implementation in Nigeria and Sierra Leone?

2. How did action of the bureaucrats shape the implementation of the UBE policy in Nigeria and Sierra Leone?

\subsection{Theoretical Framework: Klikauer (2013)}

This study draws on the theoretical understanding of managerialism articulated by Klikauer (2013) to explore the shared understanding of education policy and its implementation processes in both countries and to deepen our understanding of the architectural paradigm of policy implementation system in Nigeria and Sierra Leone. Managerialism could be explained in the value of professional managers and of the concepts and methods they use in implementing policy decisions. While acknowledging that several scholars have critiqued the theory of managerialism from different ideological positions in both negative and positive connotations, these researchers found Klikauer (2013) idea of managerialism as a concept 
relevant for the contemporary business of managing schools. This ideological position assisted the researchers to know why education has been regarded as a 'means and ends' to national and economic development in Africa continent, and provided the needed justification of why the people responsible for policy implementation are highly regarded as people with the required skill sets and be able to apply such to all areas of society on the grounds of superior ideology, expert training, and the exclusive possession of managerial knowledge necessary to efficiently run corporations, including education industry. This understanding justifies why the researchers designed one of the research questions to elicit information on how bureaucrats' skills, expertise and knowledge have impacted on their policy implementation drive, as managerialists pretend to have advanced knowledge and know-how deemed necessary to the efficient running of organizations.

It was through Klikauer, that we were able to understand how politics and system of government could impact on the efficiency level of the bureaucrats in implementing policy decisions. Previous studies have shown that politics and bureaucracy contributed to the inconsistency in the UBE implementation in the two countries. Hence, the need to explore regional managerialism of education to reshape system and management of the schools to achieve unfettered access to educational opportunities among the school-aged children in Sierra Leone and Nigeria necessitate the need for this study. Klikauer's work on critique of an ideology clearly revealed how actions or level of alignment of people assigned with implementation could affect the success or failure of policy initiative. This understanding has assisted the researchers to understand managerialism as the key ideological faming that provides information about the nuances that could influence policy decisions and affect other administrative principles. In this study, the insight from Klikauer $(2013 ; 2015)$ has helped the researchers to see how development of regional managerialism and level of alignments between the bureaucrats could enhance success in policy implementation in the two countries. This theoretical framing was considered relevant because it enabled the researchers to understand the impact of socio-economic, political and other factors behind why particular education sectors or organisations have been developed and, describe the ways in which the education policy in the two countries are currently being implemented. To eradicate the disparity in educational opportunity in these countries, a regional model of managerialism against the centralised professional bureaucratic modes of organisation that currently being practised should encouraged to cope with the demand for effective and efficient educational administration in order to meet the rising population of school-aged children yet to access education in Sierra Leone and Nigeria.

\section{Method}

This study employed a qualitative research method to elicit a deeper understanding of the implementation problems of Universal Basic Education from the bureaucrats and stakeholders who were directly involved in the implementation of the policy in both Nigerian and Sierra Leone. The rationale for using qualitative research approach was premised on providing a clearer understanding of the systemic, detailed and complex understanding of the top-down approach that was employed to enforce the policy and the contributory factors to its failure in both Nigeria and Sierra Leone. This approach also provided a reflection on how 
policy ideas and expectations were disseminated. Qualitative research provided the opportunity to explore the research problem in detail because it examined the explanation and description of "multiple perspectives; attending to the ways in which language as a social and cultural construction shapes, distorts and structures understandings" and allowed us to experience and witness the description of the problem from the vantage viewpoint of the policy actors (Patton 2001, p. 102). Patton (2001) asserted that qualitative research remains a viable approach for 'naturalistic inquiry, inductive analysis, holistic perspective, qualitative data, personal contact and insight, dynamic systems, unique case orientation, context sensitivity, emphatic neutrality and design flexibility' (p. 67). This understanding informed the choice of the qualitative research approach to study the actions of bureaucrats in the implementation of Universal Basic Education at both the Federal and District levels of policy implementation in Nigeria and Sierra Leone among primary school students.

\subsection{Research Design}

The research design was a qualitative case study in which data were collected through document analysis and interviews. In this study, interviews were conducted with key stakeholders at the federal, state and district levels who were responsible for implementing the UBE policy and interpretative documentary analysis investigated the complex issue of implementing UBE in various official documents. The choice of document analysis for this study was because the study involved identifying and selecting relevant reports and evaluating information that was relevant to the research. Duffy (2005) stated that the document analysis approach is dynamic in nature because it can be used as the central or exclusive method of research. It can also be used to examine the reliability of the evidence gathered from interviews (Duffy, 2005, p. 97). Hakim (2000) and Elton (2002) viewed document analysis as examining information that came into existence during a particular period of study.

This understanding provided the lead for researchers to seek and review documents on UBE from the UBEC, SUBEB and LGEA, and from the Legislative Committee on Education (Appendix 2). The document analysis approach assisted the researchers to focus on past records of policy implementation documents, evaluation reports, statistical data on enrolment and the implementation strategies of the programme. The choice of qualitative interviews was appropriate for this study because of the 'desire to hear from people directly how they interpret their experiences' (Heyl, 2001, p. 370). The semi-structured interview enables the researchers to gather the bureaucrats' stories and their actions, intentions, and perspectives of implementing the policy on implementation and (Patton, 2002, p. 341; Heyl, 2001). This aligns with the emphasis in qualitative research on 'understanding through looking closely at people's words, actions and records' (Cresswell, 2013; Flick, 2014) and allowing the researcher 'in an historical or descriptive way' to more closely represent the situation as experienced by the participants. 


\subsection{Data Analysis}

The data were analysed to assess how the actions and demonstrated skills of the bureaucrats impact their specific role in the implementation of the UBE initiative in the countries. Data were analysed from documents and semi- structured interviews. The interviews were digitally recorded and later transcribed in full. The researchers examined and analysed thematically and iteratively the responses of the interviewees to the UBE policy implementation, inequitable power dynamics, the politics, social, historical and cultural factors that shaped the effectiveness of the policy implementation. The interview discussions and documentary evidence exposed how policy ideas and expectations were disseminated, interpreted and implemented among the bureaucrats responsible for policy implementation and the equitable access to the UBE programme in the Nigerian and Sierra Leone context. The method of analysis aligns with understanding of the three critical processes of qualitative research methodology: preparing and organising the data; coding and recording, and the representation of the data (Cresswell, 2013; Flick, 2014).

\section{Findings}

The findings from this study was premised on the analysed documents and interviews conducted with the bureaucrats responsible for the implementation of education program in Nigeria and Sierra Leone. The reflection from the interviewees revealed that the management or administrative structure of education sector in both countries is similar in scope and operation. The three tiers (federal, state and local district) of government are adequately involved in the implementation of UBE policy in both countries. In the light of the above, the key issues from the findings are presented under the following sub-headings.

\subsection{Community Context}

One commonality among all the participants that were interviewed in Nigeria and Sierra Leone was that they have deep knowledge of the policy and the required skill sets to turn policy intent to action. The understanding of policy to practice according to the data connotes the bureaucrats' knowledge or ability at interpreting/analysing policy in the direction of what the policy should be and the processes involved in achieving the desirable outcome. The view of the Nigeria participant 2 expressed the general notion of the interviewees regarding their knowledge of turning policy into action in both countries.

It involves series of actions and it is on stages. The first one, the state has what is known as state development plan; the local government have their own action plan and the schools also have their own, known as post-school development plan. The stakeholders come together to deliberate on that action plans-what development do we wish to take place in your school this year? Stage two is now the implementation of the action plans. We have the stakeholders that are charged with the responsibilities of each of the actions-SUBEB at the state level, $L G E A$ at the local level, the federal government, and the parents (SBMC) also have their roles to play in the implementation and development of the action plan. (Nigeria participant) 


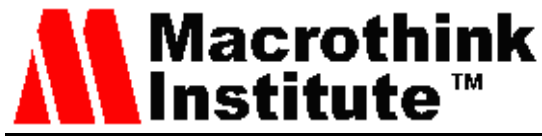

This shared understanding of policy intent provided an informed decision about the implementation of the policy. Documentary evidence from both countries affirmed that the bureaucrats have in-depth knowledge of the UBE policy and the capability to translate the policy to action. This understanding has reflected in the uniformity of the template across the two countries. This uniformity sought to ensure total compliance at all levels of implementation. This implies that the template was designed by considering the cultural and geographical diversities of the country. It explained the tenacity of the government towards eradicating the dichotomy in terms of educational opportunities associated with regions.

The hallmark of the policy was the promulgation of the UBE law-known as the Universal Basic Education Act-submitted to the legislative arms of the government in 2000, and enacted in 2004. Previous to this, there were no documents to be referred to as such, even in regard to previous education policies in Nigeria. This Act meant that UBE was not a governmental empty promise, but an intention backed by law. Among other things, the Act emphasised the constitutional rights of the states and local governments to manage basic education, and of the federal government to assist, intervene or act in partnership with the states and local governments (UBE Act, 2004, p.4).

Sierra Leone introduced free primary education in 2003, which has had a marked positive impact on the enrolment levels of boys and girls, and has declared its commitment to achieving education for all by 2015. A number of policies and legislations have been passed to support these efforts, including the Education Act of 2004 and the Child Rights Act of 2007, making basic education compulsory (UPE Act, 2004; UNDP, 2004).

The knowledge of policy engagement has enabled the bureaucrats across the two countries to record some pockets of achievement in the area of access to school among the school-aged children in both Nigeria and Sierra Leone. According to participants in both countries,

Despite the challenge of the public's perceptions regarding implementation, the bureaucrats agreed that there has been increase in the enrolment of children across all public schools in the regions. (Sierra Leone participant)

I can only feel the improvement of enrolment in the villages and less developed areas where there are little or no private schools. And it is the illiterate parents and poor parents that take their children to public schools. At least, I could remember teachers run after school-age children 15 to 16 years ago to come and enrol in schools in order to safeguard their job to avoid being retrenched by the government due to high ratio of teachers to pupils. There is increment in the number of enrolment now because of the population explosion mostly from illiterate and poor parents. (Nigeria participant)

The documentary evidence indicated that there has been increase in enrolment in public schools in the studied regions, compared with the data in Table 1. Although this increase has been marginal, it indicates that the policy has been able to achieve, to an extent, the desired outcome of ensuring access to basic education across the regions. However, across Nigeria and Sierra Leone the issue of infrastructural facilities, instructional materials, qualified resource persons- teachers, teacher aide and other administrative staffs are urgently needed in 
order to continue making progress towards the achievement of the UBE policy in both countries.

\subsection{Internal Wrangling}

From the analysed data, power struggle between the bureaucrats at all levels of policy implementation in Nigeria and Sierra Leone was mentioned as an issue affecting successful implementation of the UBE in the countries. Some of the inferences made by the interviewees informed the research team that frictions exist among the bureaucrats which has impeded the implementation of the policy. Some quote from the participants attest to this.

Ours is the main link, our job is to monitor-staying in the office does not do us any good. When we bring our report back, the management sit on it to take decisions after we would have briefed other directorates. For example, it is of no use for the Directorate of Planning, Research and Statistics to build schools in the bush indiscriminately because a commissioner comes from there, or it is a top-notch constituency. It is the $M \& E$ that we say, we need buildings here, this school is overcrowded, etcetera. We make reports of these things, but because we are teachers, I do not think it makes meanings to them. Even if PR\&S will monitor buildings, they should invite one of us to go with them. (Nigeria participant)

Internal frictions were also noticeable among the Sierra Leone bureaucrats, which was a result of the appointment process of the administrative heads. There was also the issue of disagreement between the three tiers on UBE implementation. The bureaucrats believed that their views on monitoring and supervision of UBE activities in school had not been given adequate attention which affected school enrolment. For example, in 2009, one of the Nigerian participants reported that there was a lack of teachers for core subjects in some schools, yet nothing has been done in that regard. The power of control in this context refers to a lack of alignment that resulted in frictions between the Ministry of Education (MOE) and other agencies SUBEB on UBE implementation in both countries. The friction was because the old/traditional schools were still enrolling, even though they were no longer expected to enrol students after the introduction of UBE. Other issues that were often mentioned by both the Nigeria and Sierra Leone bureaucrats in the process of implementing UBE in ranged from teacher posting, the discipline of teachers, and political influence affecting implementation. Each of these factors has affected the operational efficacies of the bureaucrats in both countries.

\section{Discussion}

The issue that has been a subject of debate among policy scholars in sub-Saharan Africa is government intentions to implement policy initiatives. Since the political independence in both countries over five decades ago, the governments of the two nations have not failed in the duty of initiating policy because the governments are interested in all-round development of the countries' endeavours, including education. This probably informed the interest of the government in revitalising the education sector that had suffered institutional failure in the past. The findings from documents analysed and the interviews with the bureaucrats pointed to the same direction of thought - government intention is informed by the need to ensure 
that citizens have unrestrained access to education opportunities. The UBE policy is the government's intention that has the support of both bureaucrats and the citizens. However, despite this overwhelming support, the intended outcome is yet to be achieved not because the bureaucrats lack working knowledge of the policy but because of the lack of alignment within the bureaucratic structure of policy implementation. Insights from the analysed data revealed that bureaucrats have the required skills, expertise and knowledge to drive, understand and channel the policy to achieve the intended outcomes and understand their roles in implementing government decisions (Key findings 1). The bureaucrats' perceptions of policy intention as an action or procedure towards achieving the intended outcome was important to understand that they have a good understanding of what is meant by the word 'policy' (Ejere,2011). Public bureaucrats understand the institutional arrangements that govern objectives and actions to address issues. These include pressure from interest groups about what they would like to achieve, and a range of ideas (including research evidence) about how best to address any given issue. It also affirmed that policymakers seemed knowledgeable on the issues that the policy sought to address. This meant that policy formulation and execution were distinct activities - clear and logical objectives for committed and skilful officials to implement (Lavis (2010); Ejere (2011); Buse, Mays \& Walt, 2005).

The challenges of implementation identified in this study are the actions of the bureaucrats responsible for the implementation of the policy. The power of control, race to outwit and the supremacy struggle among the implementing officials are the major causes of ineffective implementation of the policy in both countries (Key findings 2). The bureaucratic challenge was obvious in the manner in which the implementers approached the implementation process. There was a battle for control within the bureaucratic echelon that impeded the board of implementation's service delivery, responsiveness and agility. The coherence of vision and commitment to implementing the government intention-which should be the crucial element in driving change - was lacking with the UBE policy implementation (KF 2). The challenge of control was noticeable in the overlapping bureaucracy - a situation in which both the UBE agencies and MOEs in the countries governed the implementation of UBE tasks, which is a duty that should be the sole responsibility of the SUBEB. Exercising jurisdiction over UBE implementation by agency officials was met with great resistance from the state MOE officials. In policy implementation, the leadership commitment and interpersonal relationships among the implementing officials largely determines the overall outcome of any government policy (Lawal \& Oluwatoyin, 2011). The effect of overlapping bureaucracy has been responsible for the increase in school-age children living on the street - a situation in most major urban streets in Nigeria that has continued to attract global attention (Oni, 2008). Okechukwu and Ikechukwu (2012), Keiser (2011), Workman et al. (2010) and FGN (2008) agreed that public bureaucracy exists for the convenience of effective and efficient service delivery; however, this has not been the case with the Nigerian bureaucracy because of fragmentation and conflicting roles and responsibilities. The power of control must be addressed to achieve meaningful outcomes in any aspect of public policy, education inclusive. If not properly addressed, the implication is that policy may run out of time and be too late to solve the problem. The administrative efficiency of civil servants directly influences the 
process of political and economic development in a country. Basic education should not suffer institutional failure because of a power struggle between implementation officials.

\subsection{Limitation of the Study}

This study explored document analysis and interview data with participants from Nigeria and Sierra Leone. Most of the interviewees from Sierra Leone country were only able to provide off-record information because of the fear of losing their jobs being civil servants. This explained why most of the data quoted on the basic implementation in Sierra Leone country were from analysed documents and a few reflections from the participants in that region. This was considered as a limitation to the study.

\section{Conclusion and Recommendation}

The study has contributed to much needed understanding why the disparity in access to educational opportunity exist in Africa. It has unveiled one of the many issues militating against the successful implementation of basic education in sub-Sahara Africa. It is the high time that the issue of lack of alignment or internal wrangling in the bureaucratic structure of policy implementation to be adequately addressed in order to liberate the African continent from the shackles of poverty and underdevelopment. Bureaucrats need to come to the understanding that collective will or responsibility is the only way through which policy initiative can be realised. Therefore, pulling synergy together and eschewing the nuances associated with politics and supremacy struggle will help to realise the Education for All in 2050 since education in regions is regarded as sin quo non to national development. Recommendations that emerged from the analysed data are as follows:

1) The need to make education accessible to all school-age citizens in Nigeria and Sierra Leone is becoming increasingly critical and urgent because no nation can rise above its educational attainment. The pace at which this can be realised is hinged on the ability and action of the government and capability of the bureaucrats to effectively implement the UBE policy. Thus, the research team recommends that regional managerialism of UBE implementation should avoid the duplication of bureaucratic functions which create unhealthy rivalry among implementing officials.

2) The study has revealed factors affecting UBE policy implementation in the two countries and this was summarised under bureaucratic issue- the appointment and promotion to administrative positions. The research team recommend that appointment and promotion of bureaucrats should be devoid of undue influence from politicians and should be based on merit.

We believe that the factors that militated against the realisation of educational policy in Nigeria and Sierra Leone is deep-rooted in unethical behaviour of the political leaders in public bureaucracy which influenced primordial demands and values on the bureaucracy that negatively affected the implementation processes. Adherence to the recommendations of 
this study regarding ways to avoid these factors will ensure the development of both countries towards providing important education opportunities to its citizens.

\section{References}

Bolaji, S. D., Campbell-Evans, G., \& Gray, J. (2016). Universal basic education implementation in Nigeria. Korean Journal of Educational Policy. 13(2), 137-158.

Bolaji, S. D., Gray, R. J., \& Campbell-Evans, G. (2015). Why do policies fail in Nigeria? Journal of Educational and Social Policy, 2(5), 57-66.

Buse, K., Mays, N., \& Walt, G. (2005). Making health policy. New York: Open University Press.

Cresswell, J. W. (2013). Research design: qualitative, quantitative and mixed methods. London: Sage Publications.

Duffy, B. (2005). Analysis of documentary evidence. In J. Bell (Ed.), Doing your research project. McGraw Hill, Open University Press.

Ejere, E. I. (2011). An examination of critical problems associated with the implementation of the universal basic education programme in Nigeria. International Education Studies, 4(1), 221-229. https://doi.org/10.5539/ies.v4n1p221

Elton, G. R. (2002). The practice of history. Oxford: Blackwell.

Flick, U. (2014). An introduction to qualitative research. London: Sage Publication.

Hakim, C. (2000). Research design. London, England: Routledge.

Heyl, S. B. (2001). Ethnographic interview. In P. Atkinson, S. Delamont, A. Coffey, J. Lofland \& L. H. Lofland (Eds.), Handbook of ethnography (pp. 369-383). Thousan Oaks: Sage.

Keiser, L. R. (2011). The impact of bureaucratic structure on government eligibility decisions. Paper presented at the Public Management Research Association Conference.

Klikauer, T. (2015). What is managerialism? Lomdon: Sage publication

Klikauer, T. (2013). Managerialism: A critique of an ideology. London: Palgrave Macmillan. https://doi.org/10.1057/9781137334275

Lavis, J. (2010). Bridging the gap between research, policy and practice in low- and middleincome countries: A survey of researchers. Canadian Medical Association Journal, 182(9), 350-361. https://doi.org/10.1503/cmaj.081164

Lawal, B. O. (2007). An historical assessment of the implementation of basic education in Nigeria 1992-2000. Social Science Journals, 4(3), 403-409.

Lawal, T. \& Oluwatoyin, A. (2011). National development in Nigeria: Issues, challenges and prospects. Journal of Public Administration and Policy Research, 3(9), 237-241. 


\section{Macrothink}

International Journal of Learning and Development

ISSN 2164-4063 2018, Vol. 8, No. 2

NUT. (2008). Basic education programme in Nigeria. Nigerian union of teachers' bulletin Encyclopedia. (2010). International assessment of education United Nation human development Index. Chicago: Encyclopedia Briticannica.

Obayan, P. A. I. (2011). Report on presidential task team on education. Abuja, Nigeria: Ministry of Education.

Ogunjimi, L. O., Ajibola, C. A. \& Akah, L.U. (2009). Sustenance of education sector reforms in Nigeria through adequate participation by all the stakeholders. INGO Journal, 4(4), 104-108.

Olarenwaju, C. O., \& Folorunsho, G. A. (2009, May 30). Ten years of democracy: Nigeria's education still wobbling. Nigeria Compass Newspaper, 12.

Oni, J. O. (2008). Universality of primary education in Nigeria: trends and issues. International Journal of African \& African American Studies, 7(1), 23-31.

Patton, M. Q. (2001). Qualitative evaluation and research methods. Newbury Park, CA: Sage.

UNESCO. (2006). Information sheet on child labour in Nigeria. Ministry of Education.

UNESCO. (2015). Sierra Leone Education Sector Plan: A road map to a better future 2007-2015. Unesco Publication.

UNESCO. (2015). Annual Report 2015. Unesco Publication.

UNICEF. (2010). The millennium development goals report. Unicef Publication.

UNICEF. (1997). Annual Report for Nigeria. Unicef Publication

US Bureau. (2002). Annual Report on Sierra Leone. US-Bureau of Statistics Publication.

Workman, S., Jones, B. D. \& Jochim, A. E. (2010). Policy making bureaucratic discretion and overhead democracy. In R. F. Durant (Ed.), Handbook of America bureaucracy. New York, NY: Oxford University Press. https://doi.org/10.1093/oxfordhb/9780199238958.003.0026

World Bank. (2014). Assessment report on basic education project in Nigeria. Abuja, Nigeria.

\section{Copyright Disclaimer}

Copyright for this article is retained by the author(s), with first publication rights granted to the journal.

This is an open-access article distributed under the terms and conditions of the Creative Commons Attribution license (http://creativecommons.org/licenses/by/4.0/). 